\title{
Clinical relevance of constant power exercise duration changes in COPD
}

\author{
L. Puente-Maestu*, F. Villar" , J. de Miguel*, W.W. Stringer", P. Sanz*, M.L. Sanz', \\ J. García de Pedro* and Y. Martínez-Abad*
}

ABSTRACT: The endurance time during constant high work-rate exercise (tLIM) is used to assess exercise capacity in patients with chronic obstructive pulmonary disease and as an outcome measure for pulmonary rehabilitation. Our study was designed to establish the minimum clinically important difference for the $t$ LIM.

$t$ LIM was measured in 105 patients (86 males) before and after an 8-week outpatient pulmonary rehabilitation programme. Subjects were asked to identify, from a five-point Likert scale, the perceived change in their exercise performance immediately upon completion of the exercise tests. The scale ranged from "better" to "worse".

The mean \pm SD age was $64 \pm 5$ yrs, forced expiratory volume in $1 \mathrm{~s}$ (FEV 1 ) $47 \pm 10 \%$ and FEV 1 / forced vital capacity $54.7 \pm 16.3 \%$. Baseline $t$ LIM at $75 \%$ of the peak work rate was $397 \pm 184 \mathrm{~s}$, which increased by $62 \pm 63 \%$ after rehabilitation. In subjects who felt their exercise tolerance was "slightly better", the mean improvement was $34 \%$ in the relative improvement over the baseline value (95\% Cl 29-39)\% or 101 (86-116) s compared with 121 (109-134)\% in those who reported that their exercise tolerance was "better" and $8(2-14) \%$ in those who felt their exercise tolerance was "about the same".

Minimum clinically important improvement for $t$ LIM averaged $\sim 33 \%$ of baseline. Patients were able to distinguish at least one further additional level of benefit at $120 \%$ of baseline.

KEYWORDS: Chronic respiratory questionnaire, clinically relevant changes, constant exercise test reliability

imitation of physical activity occupies a central role in the symptom complex of patients with chronic obstructive pulmonary disease (COPD) and for that reason, improvement in exercise capacity is a key dimension of response to therapy in COPD and other chronic respiratory diseases [1]. Standardised exercise testing is a reliable and accurate means for assessing exercise performance both in clinical practice and large-scale clinical trials [2]. Several exercise-testing protocols are available, however, endurance time during constant high work-rate exercise (tLIM), i.e. above the critical power [3], can be very sensitive in detecting physiological changes induced by interventions [4, 5]. However, we have previously shown that both $t$ LIM and the change in tLIM after leg muscle training vary considerably depending on the intensity set for the constant work rate (CWR) [3]; when above the "critical power", the closer tLIM is to such a physiological point (i.e. the less stressful within the high-intensity work rates domain), the larger the expected change [3], making the test more responsive to interventions.
Published reports of clinical investigations generally provide sufficient information to judge the statistical significance of the treatment effect as measured by functional outcomes. However, the clinical interpretation of these changes would be more meaningful if clinically relevant thresholds (i.e. the minimum cut-off points that are perceived as beneficial by the patients or subjects) were defined [6-8]. A pilot attempt to estimate the minimal clinically important difference (MCID) of $t$ LIM at $75 \%$ of the peak work rate $(t$ LIM, 75$)$ arrived at a tentative figure of $105 \mathrm{~s}$ [9].

The aim of this study was, therefore, to define MCID for $t$ LIM on a cycle-ergometer. A secondary aim was to test whether different CWR intensities (75\% and $85 \%$ of the peak ramp work rate) performed differently.

\section{METHODS}

Patients diagnosed with COPD [10] according to the reference values used in our laboratory were sent to our centre for rehabilitation at the Hospital Universitario Gregorio Marañón, Madrid, Spain, and were selected for the study
AFFILIATIONS

*Servicio de Neumología, Hospital General Universitario Gregorio Marañón,

\#Fundación Jiménez Díaz, ${ }^{+}$Hospital Virgen de la Torre, CIBER Enfermedades Respiratorias (CIBERES), Madrid, Spain. - Los Angeles BioMedical Research Institute at Harbor-UCLA Medical

Center, Torrance, CA, USA.

CORRESPONDENCE

L. Puente-Maestu

Hospital General Universitario

Gregorio Marañón

Servicio de Neumología

c/ Doctor Ezquerdo 46

28007 Madrid

Spain

E-mail: Ipuente.hgugm@

salud.madrid.org

Received:

May 242008

Accepted after revision:

Feb 172009

First published online:

Feb 272009 
if they were currently nonsmoking, stable and not in need of chronic oxygen therapy [11]. Subjects were excluded if desaturation ( $<85 \%$ by pulse oximetry) was accompanied by arrhythmia or chest pain, or if the patient did not complete the training programme. All subjects signed an informed consent form as approved by our Institutional Committee for Ethics in Human Research (Comité de Ética en la Investigación Clínica del Área 1, Madrid).

The outpatient rehabilitation programme consisted of leg training on the cycle-ergometer for $45 \mathrm{~min} \cdot$ day $^{-1}$ divided into as many as three bouts, 3 days week $^{-1}$, for 8 weeks. The training began at a work rate equal to $70 \%$ of the maximal work rate (WRmax) achieved on the baseline incremental exercise test (described below). When the subjects were able to tolerate the work rate for the 45 min session, we attempted to incrementally increase the work rate by $5 \mathrm{~W}$ every week.

Incremental exercise tests were performed on an electromagnetically braked cycle-ergometer (ER-900; Jaeger, Hochberg, Germany) using a 1-min step protocol [12] at $10 \mathrm{~W} \cdot \mathrm{min}^{-1}$ to a symptom-limited maximum. Ventilation and pulmonary gas exchange were measured breath-by-breath by an cardiopulmonary exercise system (Oxycon $\alpha$; Jaeger). WRmax was defined as the maximum work rate that could be sustained for at least $30 \mathrm{~s}$. At least 1 day after the incremental test, the subjects randomly performed the two CWR tests on different days at $75 \%$ and $85 \%$ of the WRmax from the pre-training incremental test. The order of the CWR tests was randomised in sequence. All the exercise tests (both incremental and constant) were standardised with respect to the proper seat adjustment relative to leg length and pedalling cadence (60 rpm). The CWR endurance test protocol was 1 min of rest and $1 \mathrm{~min}$ of unloaded cycling before the pre-set work rate was instituted. The tests were terminated when, after standardised encouragement, the subjects were unable to continue because of symptoms. If the initial tLIM was $<120 \mathrm{~s}$ or $>1,200 \mathrm{~s}$ in either of the two tests, the work rate was increased or decreased in both the $75 \%$ and $85 \%$ tests by $10 \%$ of WRmax or by $5 \mathrm{~W}$, whichever was smaller. In total, $13(12 \%)$ of the study subjects needed work-rate adjustment, but none needed more than one adjustment. Test-retest reliability of the $75 \%$ and $85 \%$ CWR endurance and ventilatory responses were assessed in 25 consecutive subjects by repeating the tests within 2-3 days after the first one. All these tests were performed prior to the start of the leg training programme. Post-rehabilitation tests were performed within a week of the last session.

Subjective ratings of exercise capacity change after the intervention were measured by a Likert scale containing seven categories: "no change", "a little bit better (or worse)", "somewhat better (or worse)", and "much better (or worse)" $[7,13]$, and administered by the therapist after the training programme. As done previously by SINGH et al. [8], we grouped the categories "somewhat better" and "much better" into "better" and "somewhat worse" and "much worse" into "worse" to increase the power of the sample.

Quality of life was measured in all subjects by the same investigator using a version of the Chronic Respiratory Questionnaire (CRQ) [14] translated into, and validated, in Spanish [15]. The CRQ was administered just before the exercise tests. Clinically relevant changes in the dyspnoea score (CRQ-D) have been found to be 0.5 per item [13], so that a sum total of 2.5 points for the five items was considered relevant. Accordingly, four categories of CRQ-D response were defined: $\leqslant-2.5,-2.4-2.4,2.5-4.9$ and $>5$ of the baseline CRQ-D score [16].

We integrated certain statistical indexes with the two clinical benchmarks described above (subjective ratings of improvement and CRQ-D score) to "triangulate" the minimum relevant changes, as suggested by LEIDY and WYRWICH [16]. The statistical indices utilised were the percentage of change from baseline and a distribution-based approach, the effect size (defined as change from baseline to the end of the treatment divided by the SD of the whole group at baseline). Therefore, an effect of 1 corresponds to an increase equal to one SD of the parameter at baseline. In addition, we calculated the "optimal" tLIM cut-off points (i.e. those that maximised the area under the receiving operating characteristic curve (AUC)) to detect a subject's changes in their self-rating from an "about the same" or lower score to an "a little bit better" or higher score, for the subjective ratings of improvement, and changes of $<2.5$ points versus improvements of $\geqslant 2.5$ for the $C R Q-D$. Sensitivities and specificities of such cut-off points were also calculated.

tLIM exercise variables and their changes after intervention were normally distributed and are described well by their mean \pm SD values. The relationships between changes in tLIM, subjective global scale of exercise capacity and CRQ were assessed using the nonparametric Spearman's rank correlation coefficient " $\rho$ ". Reliability was evaluated by means of Bland-Altman graphical analysis [17], intra-class correlation coefficients and paired ttests. Variation coefficients were also calculated. The sample size was estimated for an $\alpha$ error of 0.05 and a power of 0.8 from the mean differences observed after recruiting the first 70 subjects (mean values for "worse", "slightly worse", "about the same", "slightly better" and "better" were (in s): -100 (-134- 65), -23.8 (-33- -14), 39 (26-53), 102 (89-116) and 544 (474-614), respectively, with an overall standard deviation of $262 \mathrm{~s})$. From these results we considered it reasonable to power the study to detect differences with one-way ANOVAs of at least $60 \mathrm{~s}$ between all groups except for the last two (slightly better and better), for which detection of a difference of $120 \mathrm{~s}$ was considered enough due to the large differences seen in the pilot study and a distribution of the sample over the categories of 10 , $10,20,30$ and $30 \%$, respectively. The estimated sample size needed was $12,12,23,34,34$ or 105 subjects, respectively. The required sample size was calculated using Ene 2.0 software (GSK Servei d'Estadística de la UAB; www.e-biometria.com/ ene-ctm/index.htm).

\section{RESULTS}

We studied 105 COPD subjects (86 males); 22 met the Global Inititaive for Chronic Obstructive Lung Disease (GOLD) II criteria and the rest, who were moderately hyperinflated and had moderate reductions in exercise capacity, met GOLD III (table 1) [10]. Patients were recruited until the total estimated number was reached, even if the expected number in the "worse" and "a little bit worse" groups could not be reached. All the participants who tolerated the $75 \%$ test were able to tolerate the $85 \%$ tests (i.e. were able to endure the $85 \%$ test for $>2 \mathrm{~min}$ ). 


\begin{tabular}{|c|c|}
\hline Variables & Mean \pm SD \\
\hline Age yrs & $64 \pm 5$ \\
\hline Height $\mathrm{cm}$ & $168 \pm 4$ \\
\hline $\mathrm{BMI} \mathbf{k g} \cdot \mathrm{m}^{-2}$ & $23 \pm 3$ \\
\hline FEV $1 \%$ pred & $46.8 \pm 10$ \\
\hline FEV1/FVC \% & $54.7 \pm 16.3$ \\
\hline${\mathrm{Pa}, \mathrm{O}_{2}}_{\mathrm{mmHg}}$ & $65 \pm 4$ \\
\hline $\mathrm{Pa}, \mathrm{CO}_{2} \mathrm{mmHg}$ & $39 \pm 4$ \\
\hline RV/TLC \% & $60.1 \pm 15.6$ \\
\hline TLC \% & $112 \pm 4.6$ \\
\hline$V^{\prime} O_{2}, \max L \cdot \min ^{-1}$ & $1.32 \pm 0.27$ \\
\hline$V^{\prime} \mathrm{O}_{2} \%$ pred & $67.5 \pm 14$ \\
\hline WRmax W & $89 \pm 23$ \\
\hline Dyspnoea CRQ & $16.7 \pm 2.8$ \\
\hline \multicolumn{2}{|c|}{$\begin{array}{l}\text { BMI: body mass index; FEV1: forced expiratory volume in } 1 \mathrm{~s} \text {; \% pred: \% } \\
\text { predicted; } \mathrm{FVC} \text { : forced vital capacity; } \mathrm{Pa}_{1} \mathrm{O}_{2} \text { : arterial oxygen tension; } \mathrm{Pa}_{1} \mathrm{CO}_{2} \text { : } \\
\text { arterial carbon dioxide tension; } \mathrm{RV} \text { : residual volume; TLC: total lung capacity; } \\
\mathrm{V}^{\prime} \mathrm{O}_{2} \text {;max: maximal oxygen uptake; } \mathrm{V}^{\prime} \mathrm{O}_{2} \text { : peak oxygen uptake; WRmax: maximal } \\
\text { work rate; } \mathrm{CRQ} \text { : Chronic Respiratory Questionnaire. }\end{array}$} \\
\hline
\end{tabular}

Both CWR tests showed excellent test-retest reliability (fig. 1), with a tendency to increase tLIM in the second repetition (table 2). Highly significant intra-class correlation coefficients $(\geqslant 0.85 ; \mathrm{p}<0.001)$ were found between test and retest assessments of endurance time, as well as of end-exercise ventilatory responses.

For the $75 \%$ and $85 \%$ CWR endurance tests, pre-treatment $t$ LIM was $397 \pm 184 \mathrm{~s}$ and $315 \pm 194 \mathrm{~s}$. The average increases in $t$ LIM after the intervention were $289 \pm 311 \mathrm{~s}$ and $138 \pm 147 \mathrm{~s}$, or $62 \pm 63 \%$ and $48 \pm 57 \%$, respectively, for the $75 \%$ and $85 \%$ CWR tests.

The distribution of responses of the questions about perceived improvement was as follows: "better", 33\% (n=35); "slightly better", 32\% ( $n=33)$; "about the same", 24\% (n=25); "slightly worse", $6 \%(n=7)$; and "worse", 5\% $(n=5)$. There were significant differences $(\mathrm{p}<0.05)$ in baseline CRQ-D scores and tLIM between the "better" group and the other groups.

The average improvement in the CRQ-D score was $5.5 \pm 5.1$. Of the subjects, $\sim 75 \%$ improved $>2.5$ points in their scores (table 3). The changes observed with the CRQ scores correlated well $(\rho=0.65, p<0.001$ for the $75 \%$ CWR test and $\rho=0.61$, $\mathrm{p}<0.001$ for the $85 \%$ CWR test), with improvements in tLIM and the CRQ-D score. A very good correlation between changes in CRQ-D and perceived improvement was found $(\rho=0.89)$.

The mean changes in daily living dyspnoea and perceived exercise tolerance, as measured by the CRQ-D, are described in tables 3 and 4, respectively. Patients needed to improve by 34 $(29-39) \%$ or $101(86-116) \mathrm{s}$ in the $75 \%$ CWR test and by 31 (25$34) \%$ or $67(61-85) \mathrm{s}$ in the $85 \%$ CWR test to perceive their tolerance to exercise as "slightly better". A further difference was found at $121(109-134) \%$ or $521(472-571) \mathrm{s}$ for the $75 \%$ CWR and at $92(81-103) \%$ or $299(263-335) \mathrm{s}$ for the $85 \%$ CWR.
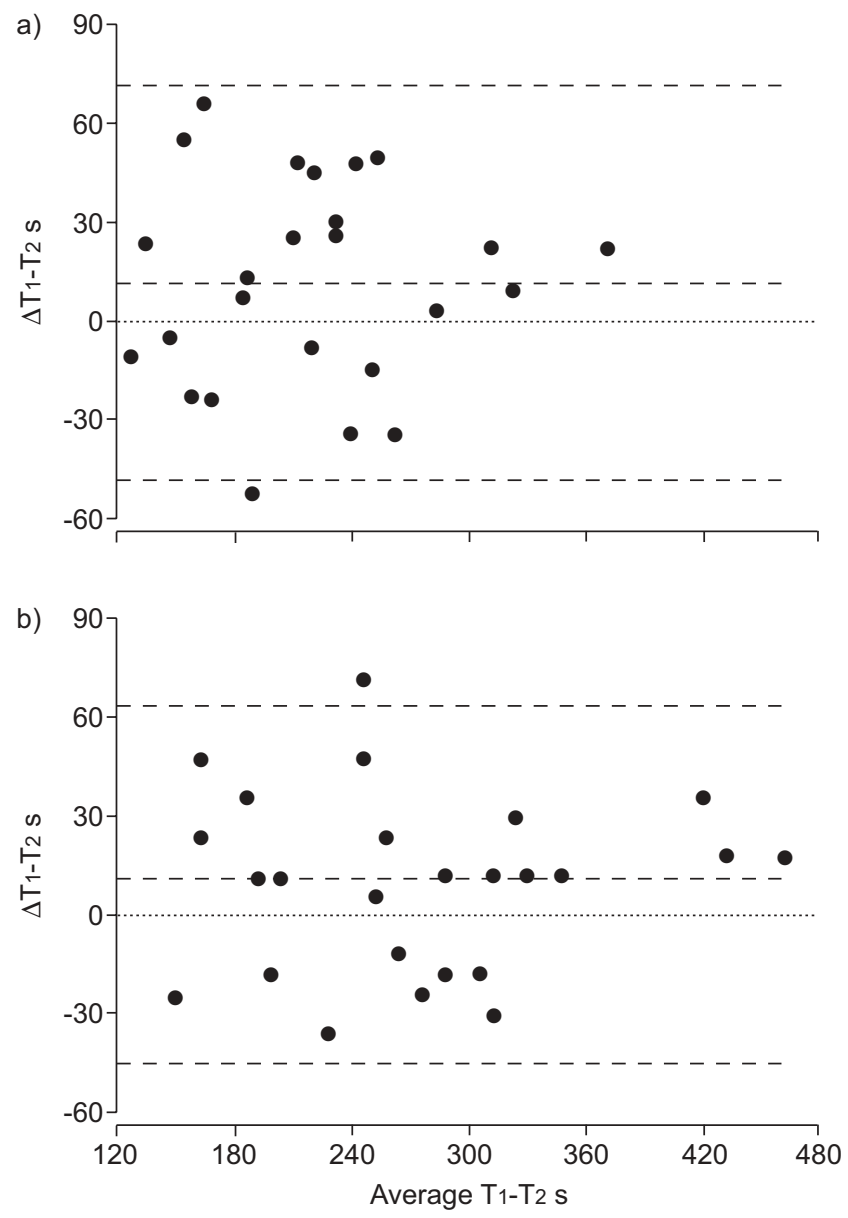

FIGURE 1. Bland and Altman diagram showing the reproducibility of the consant work-rate tests at a) $85 \%$ and b) $75 \%$ of maximal work rate. $\mathrm{T}_{1}$ : first trial; $\mathrm{T}_{2}$ : second repetition of trial 3 days after T1. - - - -: the middle line represents the average difference between the two determinations and the two outer lines are the upper and lower limits of the $95 \%$ confidence interval of the average difference.

When the effects were reported as absolute time, a relationship $(\mathrm{r} \approx 0.4)$ between baseline $t$ LIM and the magnitude of the improvements was observed (fig. 2); the apparent influence of the initial performance on the magnitude of the effects disappeared when they were standardised as a percentage over the baseline.

The "optimum" tLIM cut-off points, by receiver operating characteristic analysis (sensitivity 0.97, specificity 0.93), to detect a subject's changes in their self-rating from "about the same" to "a little bit better" were $90 \mathrm{~s}$ for tLIM,75 (sensitivity 0.9 , specificity 1.0) and $76 \mathrm{~s}$ (sensitivity 0.84 , specificity 1.0 ) for $t$ LIM,85. On analysing the percentages, the best cut-off points were $27 \%$ (sensitivity 0.87 , specificity 0.9 ) for $t$ LIM,75 and $23 \%$ (sensitivity 0.83 , specificity, 0.9 ) for $t$ LIM,85. From the point of view of their classifying power, the AUC was slightly better (AUC 0.94 (95\% CI 0.92-0.98)) for the 75\% CWR test compared with the 85\% CWR test (AUC 0.85 (95\% CI 0.82-0.88)).

The cut-off points were similar: $30(26-35) \%$ or $90(74-106) \mathrm{s}$ for the $75 \%$ CWR test and $26(21-30) \%$ or $55(39-73)$ s for the $85 \%$ CWR test when using changes in CRQ-D $\geqslant 2.5$ points as the clinical benchmark of improvement. 


\begin{tabular}{|c|c|c|}
\hline $\begin{array}{ll}\text { TABLE } 2 & \begin{array}{l}\text { Reliability } \\
\text { high-work }\end{array}\end{array}$ & $\begin{array}{l}\text { e time dur } \\
\text { e (tLIM) }\end{array}$ & nstant \\
\hline Variables & Mean \pm SD & $p$-value \\
\hline Pre-training tLIM,75 S & $420 \pm 126$ & \\
\hline Pre-training $t$ LIM,85 S & $294 \pm 90$ & \\
\hline tLIM,75 (T2-T1) s & $12.5 \pm 27.7$ & 0.054 \\
\hline$t$ LIMM,85 (T2-T1) s & $11.4 \pm 30.9$ & 0.051 \\
\hline VC $t$ LIM, $75 \%$ & $5.2 \pm 12.5$ & \\
\hline VC tLIM,85 \% & $7.3 \pm 14.8$ & \\
\hline Pre-training $V^{\prime} E, 75 L \cdot \min ^{-1}$ & $40.1 \pm 9.6$ & \\
\hline Pre-training $V^{\prime} E, 85 L \cdot \min ^{-1}$ & $41.3 \pm 10.6$ & \\
\hline$V^{\prime} E, 75\left(T_{2}-T_{1}\right) L \cdot m^{-1}$ & $0.84 \pm 1.09$ & NS \\
\hline$V^{\prime} E, 85\left(T_{2}-T_{1}\right) L \cdot m^{-1}$ & $0.76 \pm 1.22$ & NS \\
\hline VC V'E,75\% & $2.1 \pm 2.7$ & \\
\hline VC V'E,85 \% & $1.3 \pm 2.8$ & \\
\hline
\end{tabular}

$t L I M, 75$ and $t$ LIM,85: endurance to constant work-rate test at $75 \%$ and $85 \%$, respectively, of the peak work rate; $T_{1}$ and $T_{2}$ : the first and second trials, respectively, separated by 3 days; $V C$ : vital capacity; $V^{\prime} E, 75$ and $V^{\prime} E, 85$ : minute ventilation on exercise at $75 \%$ and $85 \%$, respectively, of the peak work rate; NS: nonsignificant. Note: the tLIM and $V^{\prime} E$ values shown here correspond to only the 25 subjects involved in the test-retest reliability substudy.

\section{DISCUSSION}

Our study showed that both $t$ LIM,75 and endurance to constant work-rate test at $85 \%$ of the peak work rate $(t \mathrm{LIM}, 85)$ were quite reproducible (fig. 1), which could be explained, in part, by the subjects becoming acquainted with the testing environment and procedures in the previously performed baseline incremental test. In addition, we integrated several clinical and statistical approaches to "triangulate" the MCID [16], and the different methods rendered narrow ranges of values of important differences or cut-off points for both $t$ LIM,75 and tLIM,85 (tables 3 and 4). For tLIM,75, for instance, subjects needed to improve by $101(86-116) \mathrm{s}$ or $34(29-39) \%$ to rate themselves as clinically slightly improved (table 4). Results were quite similar: $30(26-35) \%$ or $90(74-106)$ s for a significant increase in the CRQ-D score (table 3) and the "optimum" cutoff point, calculated as described in the methods, was $90 \mathrm{~s}$. Additional levels of benefit could be perceived by those with larger improvement (tables 3 and 4). Finally, we found that decreases in $t$ LIM,75 of $12(-28-3.5) \%$ or $-29(-36--22) \mathrm{s}$ were perceived by the subjects as a slight deterioration, but the sample size of the group who deteriorated was very small.

We found that, when measured in seconds, the MCID was dependent on the baseline state, but this was not the case when it was expressed as a percentage of baseline (fig. 2). Furthermore, when expressed as a percentage of baseline, the MCID were similar in both intensities, suggesting that the percentage of change over baseline is a better way of standardising the response to interventions.

tLIM during high CWR exercise (i.e. at $75-85 \%$ of the WRmax) has previously been shown to be reliable [18] and highly responsive to therapeutic interventions, such as bronchodilator therapy [5, 19-22], oxygen [23], heliox administration during exercise [24] and rehabilitation [3,4]. Work rates utilised in

\begin{tabular}{|c|c|c|c|c|}
\hline \multirow[t]{3}{*}{ TABLE 3} & $\begin{array}{l}\text { nge afte } \\
\text { ording to } \\
\text { stionnair }\end{array}$ & $\begin{array}{l}\text { eatment } \\
\text { e change } \\
\text { itial dysk }\end{array}$ & $\begin{array}{l}\text { ne diffe } \\
\text { n chron } \\
\text { ea scor }\end{array}$ & $\begin{array}{l}\text { groups } \\
\text { spiratory } \\
\text { RQ-D) }\end{array}$ \\
\hline & \multicolumn{4}{|c|}{ CRQ-D response categories } \\
\hline & $\leqslant-2.5$ & $-2.5-2.4$ & $2.5-4.9$ & $\geqslant 5$ \\
\hline Subjects $n$ & 6 & 22 & 37 & 40 \\
\hline$M / F n$ & $5: 1$ & $17: 5$ & $30: 7$ & $33: 7$ \\
\hline $\begin{array}{l}\text { Baseline } \\
\text { dyspnoea }^{\#}\end{array}$ & $16.8 \pm 5.2$ & $15.5 \pm 3.9$ & $15.5 \pm 2.5$ & $17.5 \pm 1.7$ \\
\hline Baseline $t$ LIMM,75 S & $316 \pm 113$ & $313 \pm 187$ & $315 \pm 156$ & $452 \pm 172$ \\
\hline Baseline $t$ tLIM,85 S & $214 \pm 117$ & $260 \pm 177$ & $238 \pm 157$ & $377 \pm 203$ \\
\hline$\Delta t L I M, 75 \mathrm{~S}$ & $-90 \pm 54$ & $11 \pm 34$ & $90 \pm 28$ & $546 \pm 249$ \\
\hline$\Delta t$ LIM,85 s & $-60 \pm 30$ & $1 \pm 23$ & $55 \pm 21$ & $245 \pm 124$ \\
\hline$\Delta t$ LIM,75 \% & $-30 \pm 17$ & $3 \pm 14$ & $30 \pm 13$ & $126 \pm 54$ \\
\hline$\Delta t$ LIM,85 \% & $-34 \pm 16$ & $1 \pm 16$ & $26 \pm 12$ & $75 \pm 41$ \\
\hline $\begin{array}{c}\text { Effect size at } \\
75 \%\end{array}$ & $-0.5 \pm 0.3$ & $0.1 \pm 0.2$ & $0.5 \pm 0.2$ & $3.0 \pm 1.4$ \\
\hline $\begin{array}{l}\text { Effect size at } \\
85 \%^{+}\end{array}$ & $-0.3 \pm 0.2$ & $0.0 \pm 0.1$ & $0.6 \pm 0.3$ & $1.3 \pm 0.6$ \\
\hline
\end{tabular}

Data are presented as mean $\pm \mathrm{SD}$, unless otherwise indicated. $\mathrm{M}$ : male; $\mathrm{F}$ : female; $t L M M, 75$ and $t L I M, 85$ : endurance to constant work-rate test at $75 \%$ and $85 \%$, respectively, of the peak work rate; $\Delta t\llcorner I M, 75$ and $\Delta t L I M, 85$ : improvement after leg training in the $75 \%$ and $85 \%$ tests, respectively. ${ }^{*}:$ CRQ-D score $\because: \Delta t$ LIM,75 divided by the SD of the baseline $75 \%$ test; ${ }^{+}: \Delta t$ LIM, 85 divided by the SD of the baseline $85 \%$ test.

recent clinical studies were $75-85 \%$ of maximal oxygen uptake or WRmax measured during symptom-limited incremental cardiopulmonary exercise testing [5, 18-22, 24]. Changes much larger than the proposed cut-off points are typically seen in patients after rehabilitation programmes that include intense leg training [2-4].

One limitation of our study is that we did not perform a prospective validation of the criteria obtained in this work for an independent population in different settings. Secondly, in the present study, we did not test the minimum clinically important difference for bronchodilator therapy. Prior work has demonstrated that small improvements in tLIM can be achieved with this therapy $[5,19-22]$, but effects $>100 \mathrm{~s}$ are unusual; for example, the mean increase in endurance time in a large-scale tiotropium trial was observed to be $110 \mathrm{~s}$ compared with placebo [19]. The physiological determinants of improvement after leg training are likely to be different from those after bronchodilator therapy $[3,19]$. Thirdly, we had to readjust the work rate in $13(12 \%)$ subjects. Based on previous experience $[3,4]$ we considered that tests of $<2$ min might be unreliable and tests of $>20$ min might not be stressful enough for the individual and therefore the subject might terminate them for different physiological or psychological reasons (boredom, seat pain, exhaustion of the muscles, etc.). Furthermore, while tests $<2$ min do not allow time for certain additional measurements, tests $>20 \mathrm{~min}$ are impractical. Therefore, we faced a dilemma: either to exclude the subjects or to retest them. It is doubtful that these patients represent "outliers" to the COPD population, rather they represent either an under- or 


\section{TABLE 4 Change after treatment in the different groups according to their perceived improvement}

\begin{tabular}{|c|c|c|c|c|c|}
\hline & “Worse” & "A little bit worse" & "About the same" & "A little bit better" & "Better" \\
\hline Subjects $n$ & 5 & 7 & 25 & 33 & 35 \\
\hline Baseline dyspnoea $^{\#}$ & $16.2 \pm 5.5$ & $15.5 \pm 4.1$ & $15.4 \pm 3.3$ & $15.4 \pm 3.3$ & $17.6 \pm 1.7^{*}$ \\
\hline Baseline $t$ LIM,75 S & $281 \pm 81$ & $293 \pm 176$ & $308 \pm 180$ & $384 \pm 191$ & $456 \pm 176$ \\
\hline Baseline $t$ tLIM,85 S & $169 \pm 45$ & $265 \pm 143$ & $248 \pm 177$ & $291 \pm 177$ & $379 \pm 207$ \\
\hline$\Delta t L I M, 75 \%$ & $-35 \pm 15$ & $-12 \pm 8$ & $12 \pm 12$ & $34 \pm 16$ & $121 \pm 41$ \\
\hline$\Delta t$ LIM,85 \% & $-40 \pm 17$ & $-15 \pm 14$ & $8 \pm 14$ & $31 \pm 14$ & $92 \pm 38$ \\
\hline Effect size at $75 \%^{\circ}$ & $-0.8 \pm 0.2$ & $-0.2 \pm 0.1$ & $0.2 \pm 0.1$ & $0.6 \pm 0.2$ & $3.2 \pm 1.2$ \\
\hline Effect size at $85 \%^{+}$ & $-0.5 \pm 0.1$ & $-0.2 \pm 0.1$ & $0.2 \pm 0.1$ & $0.7 \pm 0.3$ & $1.4 \pm 0.6$ \\
\hline$\triangle \mathrm{CRQ}$-D & $-5.2 \pm 2.7$ & $-1.8 \pm 0.7$ & $1.5 \pm 1.5$ & $4.2 \pm 1.2$ & $10 \pm 7$ \\
\hline
\end{tabular}

Data are presented as mean $\pm \mathrm{SD}$, unless otherwise indicated. M: male; F: female; tLIM,75 and tLIM,85: endurance to constant work-rate test at $75 \%$ and $85 \%$, respectively, of the peak work rate; $\Delta t L I M, 75$ and $\Delta t L I M, 85$ : improvement after leg training in the $75 \%$ and $85 \%$ tests, respectively; $\Delta C R Q-D$ : change in the breathlessness score of the chronic respiratory questionnaire initial dyspnoea score. ${ }^{\#}:$ CRQ-D score; ${ }^{\top}: \Delta t L I M, 75$ divided by the SD of the baseline $75 \%$ test; ${ }^{+}: \Delta t L I M, 85$ divided by the sD of the baseline $85 \%$ test. *: $p<0.05$.
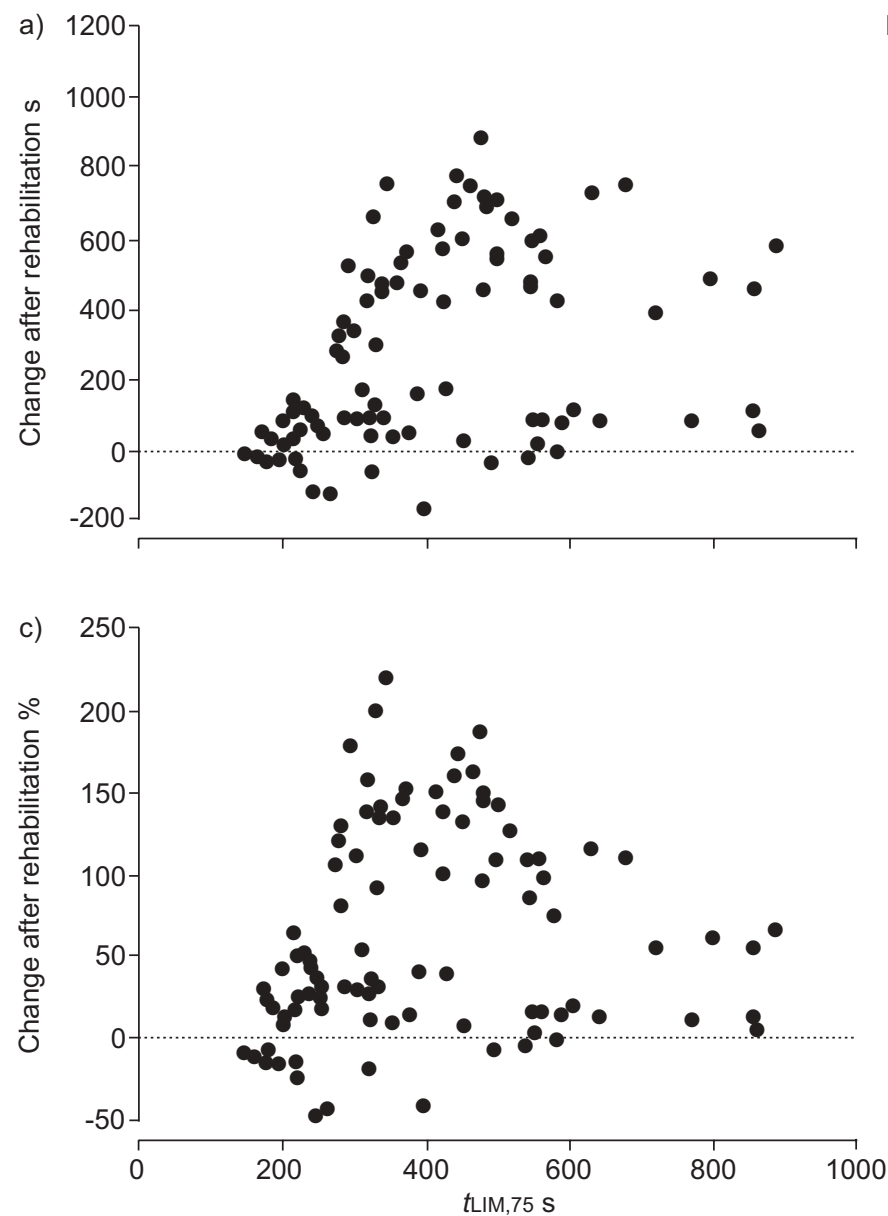

b)

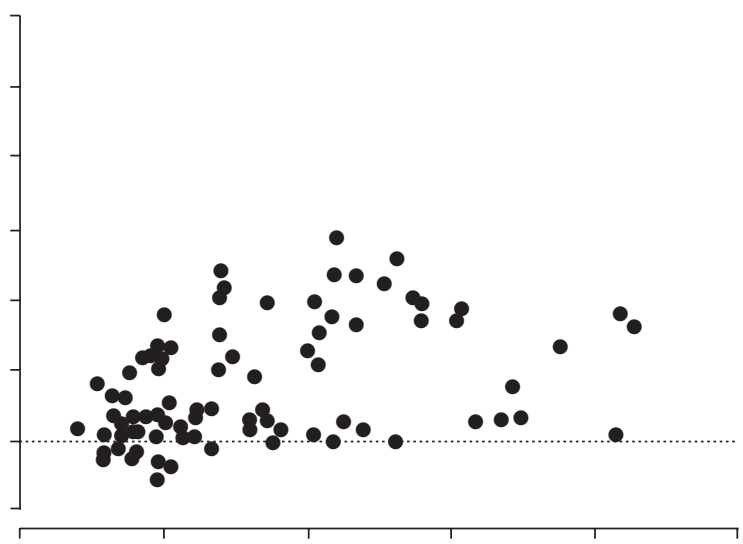

d)

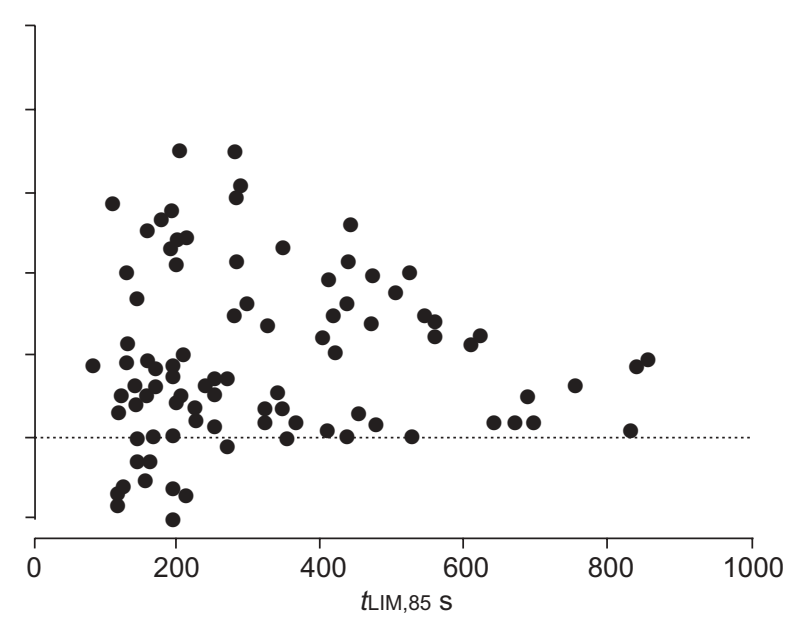

FIGURE 2. Relationship between baseline tolerance and treatment effect for duration of the initial test at $75 \%$ of the maximal work rate (tLIM,75) with respect to a) time and c) percentage and for endurance to constant work-rate test at $85 \%$ of the peak work rate $(t L I M, 85)$ with respect to $b$ ) time and $d)$ percentage. a) $r=0.41, p<0.001 ; b) r=0.40$ $p<0.001 ;$ c) $r=0.16$; and d) $r=0.02$. 
overestimation of the target work rate; moreover, we believe that in both clinical practice and trials, similar adjustments are and will be common and thus our data could be more readily extrapolated if we included such subjects. Fourthly, only 20\% of subjects enrolled were female, although this proportion is consistent with the published gender distribution of COPD in Spain $[25,26]$. Finally, in the present paper, we studied symptomatically mostly severe (GOLD III) patients and, therefore, inferences upon other populations of COPD subjects have to be made with caution. However, the types of patients included in the present study are those most frequently included in rehabilitation programmes.

In summary, our study has found that CWR tLIM is highly reproducible. We also have identified that an increase of $33 \%$ in baseline ( $\sim 100 \mathrm{~s}$ in the $75 \%$ CWR test, and $\sim 70 \mathrm{~s}$ in the $85 \%$ CWR test) are important thresholds for clinically relevant changes of $t$ LIM.

\section{SUPPORT STATEMENT}

This work was partly funded by the FIS PI052562 Grant.

\section{STATEMENT OF INTEREST}

None declared.

\section{REFERENCES}

1 Troosters T, Casaburi R, Gosselink R, et al. Pulmonary rehabilitation in chronic obstructive pulmonary disease. Am J Respir Crit Care Med 2005; 172: 19-38.

2 Nici L, Donner C, Wouters E, et al. American Thoracic Society/ European Respiratory Society statement on pulmonary rehabilitation. Am J Respir Crit Care Med 2006; 173: 1390-1413.

3 Puente-Maestu L, SantaCruz A, Vargas T, et al. Effects of training on the tolerance to high-intensity exercise in patients with severe COPD. Respiration 2003; 70: 367-370.

4 Puente-Maestu L, Sanz ML, Sanz P, et al. Comparison of effects of supervised versus self-monitored training programmes in patients with chronic obstructive pulmonary disease. Eur Respir J 2000; 15: 517-525

5 Oga T, Nishimura K, Tsukino M, et al. The effects of oxitropium bromide on exercise performance in patients with stable chronic obstructive pulmonary disease. A comparison of three different exercise tests. Am J Respir Crit Care Med 2000; 161: 1897-1901.

6 Redelmeier DA, Goldstein RS, Min ST, et al. Spirometry and dyspnea in patients with COPD. When small differences mean little. Chest 1996; 109: 1163-1168.

7 Redelmeier DA, Bayoumi AM, Goldstein RS, et al. Interpreting small differences in functional status: the six minute walk test in chronic lung disease patients. Am J Respir Crit Care Med 1997; 155: 1278-1282.

8 Singh SJ, Jones PW, Evans R, et al. Minimum clinically important improvement for the incremental shuttle walking test. Thorax 2008; 63: 775-777.

9 Casaburi R. Factors determining constant work rate exercise tolerance in COPD and their role in dictating the minimal clinically important difference in response to interventions. COPD 2005; 2: 131-136.

10 Rabe KF, Hurd S, Anzueto A, et al. Global strategy for the diagnosis, management, and prevention of chronic obstructive pulmonary disease: GOLD executive summary. Am J Respir Crit Care Med 2007; 176: 532-555.

11 Roca J, Burgos F, Sunyer J, et al. References values for forced spirometry. Group of the European Community Respiratory Health Survey. Eur Respir J 1998; 11: 1354-1362.

12 Whipp BJ, Davis JA, Torres F, et al. A test to determine parameters of aerobic function during exercise. J Appl Physiol 1981; 50: 217-221.

13 Jaeschke R, Singer J, Guyatt GH. Measurement of health status. Ascertaining the minimal clinically important difference. Control Clin Trials 1989; 10: 407-415.

14 Guyatt GH, Berman LB, Townsend M, et al. A measure of quality of life for clinical trials in chronic lung disease. Thorax 1987; 42: 773-778.

15 Guell R, Casan P, Sangenis M, et al. The Spanish translation and evaluation of a quality-of-life questionnaire in patients with chronic obstructive pulmonary disease. Arch Bronconeumol 1995; 31: 202-210

16 Leidy NK, Wyrwich KW. Bridging the gap: using triangulation methodology to estimate minimal clinically important differences (MCIDs). COPD 2005; 2: 157-165.

17 Bland JM, Altman DG. Measuring agreement in method comparison studies. Stat Methods Med Res 1999; 8: 135-160.

18 van 't Hul A, Gosselink R, Kwakkel G. Constant-load cycle endurance performance: test-retest reliability and validity in patients with COPD. J Cardiopulm Rehabil 2003; 23: 143-150.

19 O'Donnell DE, Fluge T, Gerken F, et al. Effects of tiotropium on lung hyperinflation, dyspnoea and exercise tolerance in COPD. Eur Respir J 2004; 23: 832-840.

20 O'Donnell DE, Voduc N, Fitzpatrick M, et al. Effect of salmeterol on the ventilatory response to exercise in chronic obstructive pulmonary disease. Eur Respir J 2004; 24: 86-94.

21 Maltais F, Hamilton A, Marciniuk D, et al. Improvements in symptom-limited exercise performance over $8 \mathrm{~h}$ with once-daily tiotropium in patients with COPD. Chest 2005; 128: 1168-1178.

22 Oga T, Nishimura K, Tsukino M, et al. A comparison of the effects of salbutamol and ipratropium bromide on exercise endurance in patients with COPD. Chest 2003; 123: 1810-1816.

23 Emtner M, Porszasz J, Burns M, et al. Benefits of supplemental oxygen in exercise training in nonhypoxemic chronic obstructive pulmonary disease patients. Am J Respir Crit Care Med 2003; 168: 1034-1042.

24 Palange $P$, Valli G, Onorati $P$, et al. Effect of heliox on lung dynamic hyperinflation, dyspnea, and exercise endurance capacity in COPD patients. J Appl Physiol 2004; 97: 1637-1642.

25 Pena VS, Miravitlles M, Gabriel R, et al. Geographic variations in prevalence and underdiagnosis of COPD: results of the IBERPOC multicentre epidemiological study. Chest 2000; 118: 981-989.

26 Nowak D, Berger K, Lippert B, et al. Epidemiology and health economics of COPD across Europe: a critical analysis. Treat Respir Med 2005; 4: 381-395. 